\title{
PENILAIAN NILAI WAJAR SAHAM PT CIPUTRA DEVELOPMENT TBK
}

\author{
Sheane \\ Program Studi Magister Manajemen Universitas Tarumanagara \\ sheane91@gmail.com
}

\begin{abstract}
An investor could invest by buying companies' stocks. Therefore, it is crucial for investors to know the fair value of shares of a company to anticipate the risks and benefits. The fair value of shares reflects the value of that company. This research is aimed to assess the fair value of shares of PT. Ciputra Development Tbk, whether its value is above or below the market price. This research was conducted using secondary data, which are the company's prospects, yearly report, and other official publication. Quantitative analysis was chosen to process and analyse the data collected. Method used in this valuation is the Discounted Cash Flow method with Free Cash Flow to Firm model and Relative Valuation with Price Earnings Ratio model. The result of the valuation would be useful to be used as the basis for decision making on investing, whether to buy, hold or sell the stock. Based on the calculated stock value, it was obtained that the fair value of shares of PT. Ciputra Development Tbk, using discounted free cash flow to firm method, is Rp 1.092,- which means the stock price of PT. Ciptura Development Tbk is over the market price or overvalued in comparison to its intrinsic value. On the other hand, using price earning ratio as the chosen method shows that the fair value of shares is Rp. 1.262,4 per stock which means the price of PT. Ciputra Development Tbk stock is under the market price or undervalued towards its intrinsic value.
\end{abstract}

Keywords : Valuation, Discounted Free Cash Flow to Firm, Price Earning Ratio (PER), overvalued, undervalued

\section{PENDAHULUAN}

Sebelum berinvestasi dalam suatu saham, investor harus mengetahui harga wajar dari saham tersebut terlebih dahulu dengan cara membandingkan harga wajar saham dengan harga pasar yang berlaku. Tujuan utamanya adalah untuk memilih perusahaan yang sahamnya undervalued atau overvalued. Investor yang menjual saham pada waktu overvalued akan mendapat keuntungan (capital gain) tetapi investor yang membeli pada saat saham overvalued akan menderita kerugian (capital loss). Investor yang sebelumnya telah memiliki saham dalam portofolionya, jika saham overvalued akan segera melepasnya (cut loss) dan jika undervalued akan tetap mempertahankannya (hold).

Dalam menilai harga saham ada 2 metode analisis yang sering digunakan. Pertama dengan analisis teknikal dimana investor menganalisis harga saham berdasarkan tren harga yang terbentuk di pasar (historical price). Sedangkan yang ke dua adalah dengan analisis fundamental, menurut Husnan (2001;315), "analisis fundamental mencoba memperkirakan harga saham dimasa yang akan datang dengan mengestimasi nilai faktor-faktor fundamental yang mempengaruhi harga saham di masa yang akan datang dan menetapkan hubungan variabel-variabel tersebut sehingga di peroleh taksiran harga saham". Manfaat dari analisis fundamental adalah untuk menentukan nilai instrinsik sebuah saham.

Menurut M. Sayyidin Noor dan Made Dudy Satyawan (2014), menyatakan bahwa Penilaian harga wajar saham dapat dilakukan jika terlebih dahulu menentukan tingkat imbal hasil yang disyaratkan oleh investor. Tingkat imbal hasil yang disyaratkan investor merupakan tingkat return minimum yang diharapkan oleh investor sehingga investor bersedia melakukan investasi. 
Sektor properti merupakan salah satu sektor terpenting di suatu negara. Hal ini dapat dijadikan indikator untuk menganalisis kesehatan ekonomi suatu negara. Menurut Santoso (2009) industri properti merupakan salah satu sektor yang memberikan sinyal jatuh atau sedang bangunnya perekonomian suatu negara. Hal ini menandakan bahwa semakin banyak perusahaan yang bergerak dibidang sektor properti mengindikasikan semakin berkembangnya perekonomian di Indonesia.

Perkembangan sektor properti tentu saja akan menarik minat investor dikarenakan kenaikan harga tanah dan bangunan yang cenderung naik, supply tanah bersifat tetap sedangkan demand akan selalu bertambah besar seiring dengan pertambahan jumlah penduduk serta bertambahnya kebutuhan manusia akan tempat tinggal, perkantoran, pusat perbelanjaan, dan lain-lain.

Di negara-negara maju dan berkembang, pembangunan dan bisnis properti sedang mengalami pertumbuhan yang pesat, hal ini pun terjadi di Indonesia. Saham perusahaan properti di Indonesia mulai diminati ketika tahun 2000, hal itu juga yang menyebabkan banyak perusahaan yang melakukan listing di Bursa Efek Indonesia agar saham perusahaan dapat dibeli oleh investor.

Pembangunan properti yang cukup meningkat menandakan mulai adanya perbaikan ekonomi yang signifikaan ke arah masa depan yang lebih baik. Karena hal itu penulis melakukan penelitian yang berjudul "PENILAIAN NILAI WAJAR SAHAM PT CIPUTRA DEVELOPMENT TBK”.

Tujuan dari penelitian ini : Mengetahui nilai wajar PT. Ciputra Development Tbk dengan menggunakan metode Discounted Free Cash Flow to Firm (FCFF) dan Price Earning Ratio (PER). Dan membandingkan nilai wajar saham PT. Ciputra Development Tbk dengan harga pasar saham (market price), sehingga dapat diketahui apakah harga saham PT. Ciputra Development Tbk undervalued atau overvalued.

Manfaat yang didapat dalam penelitian ini :

Bagi Investor, Hasil penelitian ini di harapakan dapat membantu investor sebagai pertimbangan dalam pengambilan keputusan untuk berinvestasi di PT Ciputra Development Tbk.

Bagi Masyarakat, Hasil penelitian ini diharapkan dapat memberikan informasi tambahan dibidang keuangan terutama data yang berkaitan dengan penilaian harga saham perusahaan target.

\section{TINJAUAN PUSTAKA}

Penilaian (valuation) adalah proses penentuan berapa harga yang wajar untuk suatu saham (Parahita,2008)

Menurut Damodaran (2002), secara garis besar ada 3 pendekatan yang digunakan dalam melakukan valuasi, yaitu :

1. Relative Valuation adalah suatu model valuasi yang menilai suatu aset melalui perbandingan dengan harga dari aset - aset lain yang sama. Metode perhitungan yang biasanya digunakan untuk melakukan perbandingan adalah price earning rasio (PER) dan price-book value rasio (PBV).

2. Contingent claim valuation merupakan suatu metode valuasi dengan menggunakan pendekatan option pricing model untuk menilai suatu aset yang memiliki sifat seperti option.

3. Discounted cash flow valuation adalah nilai suatu aset merupakan presen value (PV) dari perkiraan arus kas yang akan dihasilkan di masa depan (expexted future cash flows) dari suatu aset yang didiskontokan dengan menggunakan suatu discount rate tertentu. 
Saham Menurut Kismono (2001;416), saham merupakan sebuah piagam yang berisi aspekaspek penting bagi perusahaan, termasuk hak dari pemilik saham dan hak khusus yang dimilikinya berkaitan dengan kepemilikan saham. Contohnya adalah hak mendapatkan pendapatan tetap dari perusahaan di samping punya kewajiban untuk ikut menanggung risiko bila perusahaan dilikuidasi. Pemilik saham juga berhak mengontrol perusahaan sesuai dengan kapasitas (jumlah) saham yang dimilikinya melalui rapat umum pemegang saham dengan menggunakan hak suara yang dimilikinya.

Discounted Cash Flow Valuation Discounted cash flow valuation (DCF) adalah salah satu metode valuasi dengan menggunakan pendekatan fundamental analysis dan merupakan dasar untuk metode valuasi lainnya. Model valuasi DFC memiliki tiga variasi perhitungan yang dapat digunakan untuk melakukan analisis valuasi saham yang sesuai dengan kebutuhan masing-masing analisis. Ketiga variasi tersebut adalah dividen discounted model, free cash flow to equity dan free cash flow to firm. (Damodaran, 2002)

Free Cash Flow to Firm merupakan cash flow atau arus kas yang tersedia bagi seluruh claimholders, baik untuk kreditur (bondholders) maupun pemegang saham baik untuk common stockholders atupun preferred stockholders (Damodaran, 2002)

Price Earning Ratio merupakan suatu rasio yang lazim dipakai untuk mengukur harga pasar (market price) setiap lembar saham biasa dengan laba per lembar saham (Simamore, 2000:531).

\section{METODE PENELITIAN}

Penelitian ini dilakukan menggunakan data sekunder, yaitu prospektus perusahaan, laporan tahunan perusahaan, dan publikasi resmi lainnya. Teknik pengolahan dan analisis data dalam penelitian ini menggunakan analisis kuantitatif. Teknik pengumpulan data dengan cara dokumentasi berupa data histori laporan keuangan PT Ciputra Development Tbk di Bursa Efek Indonesia tahun 2013 sampai 2017.

\section{HASIL PENELITIAN}

\section{Metode Discounted Free Cash Flow to Firm}

Untuk dapat melakukan valuasi menggunakan Discounted Cash Flow to Firm maka terlebih dahulu dihitung Free Cash Flof to Equity (FCFE) dimana data Cash Flow berasal dari aktivitas operasi, capital expenditure, serta net borrowing. FCFE awal merupakan FCFE dimana Cash Flow dari operasi dikurang dengan FC Investasi ditambah Net Borrowing.Parameter lain yang perlu dilengkapi sehingga Nilai Intrinsik PT Ciputra Development Tbk berdasarkan FCFE dapat diketahui adalah Expenditure return (r) serta tingkat pertumbuhan (growth). Table dibawah ini merupakan formulasi step-by-step perhitungan DCF berdasarkan rumus sebagai berikut:

2000)

$$
\text { Value of Equity }=\frac{F C F E 1}{r-g}=\frac{F C F E 0 \times(1+g)}{r-g} \ldots . . . .(\text { Copeland, Koller, Murrin, }
$$

Dalam melakukan penilaian terhadap harga saham wajar PT Ciputra Development Tbk (CTRA) dengan menggunakan laporan keuangan yang telah diaudit dari tahun 2013 - 2017.

Penulis menghitung WACC dari PT Ciputra Development Tbk (CTRA) dengan cara sebagai berikut :

Rumus biaya modal rata-rata tertimbang menurut Amin Widjaja (2001) adalah :

$$
\mathrm{WACC}=((\mathrm{D} \times \mathrm{Rd}) \mathrm{X}(1-\mathrm{Tax})+(\mathrm{E} \times \mathrm{Re}))
$$

Dimana :

$\mathrm{D} \quad=$ Tingkat Modal

$\mathrm{Rd} \quad=$ Cost of Debt

Tax = Tingkat Pajak 


$$
\begin{aligned}
& \text { E = Tingkat Modal dan Ekuitas } \\
& \mathrm{Re} \quad=\text { Cost of Equity } \\
& \mathrm{D}=\frac{\text { Total Utang }}{\text { Total Utang dan Ekuitas }} \times 100 \% \\
& \mathrm{D}=\frac{16.255 .398 j u t a}{31.706 .163 j u t a} \times 100 \% \\
& \mathrm{D}=51 \% \\
& \mathrm{E}=\frac{\text { Total Ekuitas }}{\text { Total Utang dan Ekuitas }} \times 100 \% \\
& \mathrm{E}=\frac{15.450 .765 \text { juta }}{31.706 .163 \text { juta }} \times 100 \% \\
& \mathrm{E}=49 \%
\end{aligned}
$$

* Data tersebut diambil dari laporan keuangan yang telah diaudit tahun 2017

- Pinjaman PT Ciputra Development Tbk pada tahun 2017 terdiri dari :

Pinjaman PT Ciputra Development Tbk

\begin{tabular}{|l|r|c|}
\hline & Nominal & Tingkat Bunga \\
\hline Pinjaman jangka Pendek & & \\
- PT Bank Mandiri (Persero) Tbk & 445.000 .000 .000 & $10 \%-10.75 \%$ \\
- PT Bank Central Asia Tbk & 116.344 .000 .000 & $9.75 \%$ \\
- PT Bank ICBC Indonesia & 81.000 .000 .000 & $9.75 \%-10.75 \%$ \\
- PT Bank Tabungan Negara (Persero) Tbk & 73.376 .000 .000 & $11 \%-12 \%$ \\
- PT Bank CIMB Niaga Tbk & 70.000 .000 .000 & $9.25 \%-9.75 \%$ \\
- PT Bank Rakyat Indonesia (Persero) Tbk & 60.941 .000 .000 & $11 \%-12 \%$ \\
- PT Bank Nusantara Parahyangan Tbk & 32.451 .000 .000 & $12 \%$ \\
- PT Bank OCBC NISP Tbk & 9.907 .000 .000 & $0,50 \%$ \\
& & \\
Pinjaman jangka Panjang & & \\
- PT Bank ICBC Indonesia(ICBC) & 921.743 .000 .000 & $11.25 \%$ \\
- PT Bank Mandiri (Persero) Tbk & 687.950 .000 .000 & $9.75 \%$ \\
- PT Bank Central Asia Tbk & 245.097 .000 .000 & $10.25 \%$ \\
- PT Bank Negara Indonesia (Persero) Tbk & 241.545 .000 .000 & $10.75 \%$ \\
- International Finance Corporation (IFC) & 155.802 .000 .000 & $3.15 \%$ \\
- PT Bank Rakyat Indonesia (Persero) Tbk & 147.637 .000 .000 & $10.49 \%$ \\
- PT Bank Tabungan Negara (Persero) Tbk & 102.655 .000 .000 & $11.25 \%$ \\
- PT Bank Maybank Indonesia Tbk & 17.821 .000 .000 & $12.5 \%$ \\
- PT Bank CIMB Niaga Tbk & 15.104 .000 .000 & $11.5 \%$ \\
- PT Bank OCBC NISP Tbk & 12.562 .000 .000 & $0.5 \%$ \\
\hline
\end{tabular}


Tingkat suku bunga yang digunakan adalah $(10,3 \%+9,75 \%+10,25 \%+11,5 \%+9,5 \%+$ $11,5 \%+12 \%+0,5 \%+11,25 \%+9,75 \%+10,25 \%+10,75 \%+3,15 \%+10,49 \%+11,25 \%+12,5 \%+11$, $5 \%+0,5 \%) / 18=9,26 \%$.

- Pajak penghasilan Perseroan yang berlaku di Indonesia sesuai undang - undang PPh No.36 Tahun 2008 tarif pasal 17 yaitu 25\% dari penghasilan kena pajak.

- Untuk mengetahui besarnya cost of equity $\left(\mathrm{k}_{\mathrm{e}}\right)$ menggunakan rumus berikut :

$$
\mathrm{k}_{\mathrm{e}}=\mathrm{R}_{\mathrm{f}}+\beta\left(\mathrm{R}_{\mathrm{m}}-\mathrm{R}_{\mathrm{f}}\right)
$$

Dimana sudah diketahui sebelumnya bahwa

- Besarnya Rf (risk free rate) menggunakan asumsi tingkat suku bunga BI sebagai dasar perhitungan, yaitu sebesar 4,25\% www.bi.go.id periode 14 Desember 2017)

- $\quad \beta$ PT Ciputra Development Tbk adalah 0,91

- Besarnya Rm (return of market) adalah $11,16 \%$

$$
R m=\frac{I H S G t-I H S G t-1}{I H S G t-1}
$$

$R m=$ Rata-rata tingkat pengembalian

IHSGt $=$ Indeks harga saham gabungan periode $\mathrm{t}$

IHSGt-1= Indeks harga saham gabungan periode $\mathrm{t}-1$

Sehingga diperoleh sebagai berikut :

Cost of Equity $=\mathrm{rf}+\beta \times$ (rm - rf)

Cost of Equity $=4,25 \%+(0,91 \times(11,16 \%-4,25 \%))$

Cost of Equity $=4.25 \%+(0,91 \times 6,91 \%)$

Cost of Equity $=4,25 \%+6,29 \%$

Cost of Equity $=10,54 \%$

Jadi cost of equity $\left(\mathrm{k}_{\mathrm{e}}\right)$ diperoleh sebesar 10,54\% untuk digunakan sebagai dasar perhitungan WACC PT Ciputra Development Tbk.

Perhitungan WACC adalah sebagai berikut :

$\mathrm{WACC}=((51 \% \times 9,26 \%) \times(1-25 \%))+(49 \% \times 10,54 \%)$

$\mathrm{WACC}=(4,72 \% \times 75 \%)+5,16 \%$

$\mathrm{WACC}=3,54 \%+5,16 \%$

$\mathrm{WACC}=8,70 \%$

Rekap asumsi dari perhitungan Penulis

\begin{tabular}{|l|r|r|r|r|r|}
\hline Asumsi : & 2018F & 2019F & 2020F & 2021F & 2022F \\
\hline Sales growth & $10 \%$ & $10 \%$ & $10 \%$ & $10 \%$ & $10 \%$ \\
\hline Expected gross margin & $50 \%$ & $50 \%$ & $50 \%$ & $50 \%$ & $50 \%$ \\
\hline Operating cost (SGA expenses) - \% of sales & $16 \%$ & $16 \%$ & $16 \%$ & $16 \%$ & $16 \%$ \\
\hline Capex - \% of sales growth & $10 \%$ & $10 \%$ & $10 \%$ & $10 \%$ & $10 \%$ \\
\hline Net working capital - \% of sales & $5 \%$ & $5 \%$ & $5 \%$ & $5 \%$ & $5 \%$ \\
\hline
\end{tabular}

\begin{tabular}{|l|r|}
\hline Income tax rate & $25 \%$ \\
\hline Long-term growth rate & $3 \%$ \\
\hline Discount rate (WACC) & $8,70 \%$ \\
\hline
\end{tabular}

Sumber : hasil olahan Penulis 
Perhitungan Free Cash Flow to Firm

(dalam jutaan rupiah)

\begin{tabular}{|l|c|c|c|c|r|}
\hline Asumsi : & $\mathbf{2 0 1 8 F}$ & $\mathbf{2 0 1 9 F}$ & $\mathbf{2 0 2 0 F}$ & $\mathbf{2 0 2 1 F}$ & \multicolumn{2}{c|}{$\mathbf{2 0 2 2 F}$} \\
\hline Calculation of Free Cash Flows & $\mathbf{1}$ & $\mathbf{2}$ & $\mathbf{3}$ & $\mathbf{4}$ & $\mathbf{5}$ \\
\hline Sales growth & 7.087 .077 & 7.795 .784 & 8.575 .363 & 9.432 .899 & 10.376 .189 \\
\hline Direct cost (excl. depre exp) & 3.543 .538 & 3.897 .892 & 4.287 .681 & 4.716 .450 & 5.188 .094 \\
\hline Gross profit & $\mathbf{3 . 5 4 3 . 5 3 8}$ & $\mathbf{3 . 8 9 7 . 8 9 2}$ & $\mathbf{4 . 2 8 7 . 6 8 1}$ & $\mathbf{4 . 7 1 6 . 4 5 0}$ & $\mathbf{5 . 1 8 8 . 0 9 4}$ \\
\hline & & & & & \\
\hline SGA expenses (excl. depr. Exp) & 1.133 .932 & 1.247 .325 & 1.372 .058 & 1.509 .264 & 1.660 .190 \\
\hline EBITDA & $\mathbf{2 . 4 0 9 . 6 0 6}$ & $\mathbf{2 . 6 5 0 . 5 6 7}$ & $\mathbf{2 . 9 1 5 . 6 2 3}$ & $\mathbf{3 . 2 0 7 . 1 8 6}$ & $\mathbf{3 . 5 2 7 . 9 0 4}$ \\
\hline & & & & & \\
\hline Depreciation and amortization & 297.999 & 301.188 & 304.696 & 308.555 & 312.800 \\
\hline EBIT & $\mathbf{2 . 1 1 1 . 6 0 7}$ & $\mathbf{2 . 3 4 9 . 3 7 9}$ & $\mathbf{2 . 6 1 0 . 9 2 7}$ & $\mathbf{2 . 8 9 8 . 6 3 1}$ & $\mathbf{3 . 2 1 5 . 1 0 4}$ \\
\hline Other inc.(exp), net & - & - & - & - & - \\
\hline Net taxable earning & 2.111 .607 & 2.349 .379 & 2.610 .927 & 2.898 .631 & 3.215 .104 \\
\hline & & & & & \\
\hline Taxes & $\mathbf{5 2 7 . 9 0 2}$ & $\mathbf{5 8 7 . 3 4 5}$ & $\mathbf{6 5 2 . 7 3 2}$ & $\mathbf{7 2 4 . 6 5 8}$ & $\mathbf{8 0 3 . 7 7 6}$ \\
\hline NOPAT & $\mathbf{1 . 5 8 3 . 7 0 5}$ & $\mathbf{1 . 7 6 2 . 0 3 4}$ & $\mathbf{1 . 9 5 8 . 1 9 5}$ & $\mathbf{2 . 1 7 3 . 9 7 3}$ & $\mathbf{2 . 4 1 1 . 3 2 8}$ \\
\hline
\end{tabular}

\begin{tabular}{|l|r|r|r|r|r|}
\hline Add back depre. And amort & 297.999 & 301.188 & 304.696 & 308.555 & 312.800 \\
\hline Subtract Capital Expenditure & 708.708 & 779.578 & 857.536 & 943.290 & 1.037 .619 \\
\hline $\begin{array}{l}\text { Subtract New Net Working } \\
\text { Capital }\end{array}$ & 32.214 & 35.435 & 38.979 & 42.877 & 47.164 \\
\hline Free Cash Flow & $\mathbf{1 . 1 4 0 . 7 8 3}$ & $\mathbf{1 . 2 4 8 . 2 0 8}$ & $\mathbf{1 . 3 6 6 . 3 7 6}$ & $\mathbf{1 . 4 9 6 . 3 6 1}$ & $\mathbf{1 . 6 3 9 . 3 4 5}$ \\
\hline
\end{tabular}

Sumber : hasil olahan Penulis

Selanjutnya Penulis akan menghitung besarnya terminal value untuk mengetahui berapa nilainya pada tahun 2022 yaitu:

$\mathrm{V}_{\text {terminal }}=\frac{F C F F 2022}{(\mathrm{r}-\mathrm{g})}$

Dimana

Terminal Value $=\frac{\text { Free Cash Flow } 2022 \times(1+\text { Long Term Growth })}{(\text { WACC }- \text { Long Term Growth })}$

Free Cash Flow tahun 2022 adalah Rp. 1.639.345 juta

WACC $(\mathrm{r}) \quad=8,70 \%$

Long term growth $(\mathrm{g}) \quad=3 \%$

Terminal Value $=\frac{R p \cdot 1.639 .345 \times(1+3 \%)}{(8,70 \%-3 \%)}$

Sehingga diperoleh :

Terminal Value $=\frac{R p \cdot 1 \cdot 688.525,35}{(5,7 \%)}$

Terminal Value $=$ Rp. 29.623.251,75 juta

Dari perhitungan terminal value diatas dapat diperoleh bahwa nilainya adalah Rp. 29.623.251,75 juta. Nilai ini yang digunakan untuk dasar menghitung nilai saat ini (tahun 2017) atas pertumbuhan arus kas pada tahun 2022 sampai seterusnya. 
Dari hasil perhitungan cash flow yang diperoleh dari tahun 2018 sampai 2022, kemudian di-present value (PV) kan untuk mengetahui berapa nilai enterprice value atau nilai aktiva perusahaan saat ini (tahun 2017). Dari hasil olah data, diperoleh sebagai berikut :

- Tahun 2018

$$
\begin{aligned}
& \text { PV2018 }=\frac{F C C 2018}{(1+W A C C)^{1}} \\
& \text { PV2018 }=\frac{R p \cdot 1.140 .783}{(1+8,70 \%)^{1}} \\
& \text { PV2018 }=\text { Rp. 1.049.478,38 juta }
\end{aligned}
$$

- $\quad$ Tahun 2019

$$
\begin{aligned}
& \text { PV2019 }=\frac{F C C 2019}{(1+W A C C)^{2}} \\
& \text { PV2019 }=\frac{R p .1 .248 .208}{(1+8,70)^{2}} \\
& \text { PV2019 }=\text { Rp.1.056.398,74 juta }
\end{aligned}
$$

- Tahun 2020

$$
\begin{aligned}
\text { PV2020 } & =\frac{F C C 2020}{(1+W A C C)^{3}} \\
\text { PV2020 } & =\frac{R p \cdot 1.366 .376}{(1+8,70)^{3}} \\
\text { PV2020 } & =\text { Rp. } 1.063 .852,93 \text { juta }
\end{aligned}
$$

- Tahun 2021

$$
\begin{aligned}
& \text { PV2021 }=\frac{F C C 2021}{(1+W A C C)^{4}} \\
& \text { PV2021 }=\frac{R p \cdot 1.496 .361}{(1+8,70)^{4}} \\
& \text { PV2021 }=\text { Rp.1.071.810,99 juta }
\end{aligned}
$$

- Tahun 2022

$$
\begin{aligned}
\text { PV2022 } & =\frac{F C C 2022}{(1+W A C C)^{5}} \\
\text { PV2022 } & =\frac{R p \cdot 1 \cdot 639.345}{(1+8,70)^{5}} \\
\text { PV2022 } & =\text { Rp. } 1.080 .245,93 \text { juta }
\end{aligned}
$$

- Tahun 2022

$$
\begin{aligned}
& \text { PV2022 }=\frac{\text { Terminal Value } 2022}{(1+W A C C)^{5}} \\
& \text { PV2022 }=\frac{R p \cdot 29 \cdot 623 \cdot 251,75}{(1+8,70)^{5}} \\
& \text { PV2022 }=\text { Rp. } 19.520 .233,53 \text { juta }
\end{aligned}
$$

Enterprice value (EV) PT Ciputra Development pada akhir tahun 2017 adalah

$\mathrm{EV}=$ Rp. 1.049.478,38 juta + Rp. 1.056.398,74 juta + Rp. 1.063.852,93 juta

$$
\text { + Rp. 1.071.810,99 juta + Rp. 1.080.245,93 juta + Rp 19.520.233,53 juta }
$$

$\mathrm{EV}=\mathrm{Rp} .24 .842 .020,5$ juta

Setelah mengetahui enterprice value, maka untuk mendapatkan nilai ekuitas perusahaan (equity value) yaitu dengan mengurangkan hutang pinjaman perusahaan(debts).

Equity Value $=$ Enterprise Value - Debts

Equity Value = Rp. 24.842.020,5 juta - Rp. 4.596.106 juta

Equity Value $=$ Rp. 20.245.914,5 juta

Dengan menggunakan equity value dan saham yang beredar (outstanding shares), maka akan diperoleh harga per lembar saham (price per share). 


$$
\text { Price per share }\left(\text { in IDR) }=\frac{\text { Equity Value }}{\text { Number of Outstanding Shares }}\right.
$$

Diketahui bahwa jumlah saham yang beredar pada laporan audit tahun 2017 adalah 18.535 juta lembar saham sehingga diperoleh :

$$
\begin{aligned}
& \text { Harga per lembar saham }=\frac{R p .20 .245 .914,5 \text { juta }}{18.535 \text { juta }} \\
& \text { Harga per lembar saham }=\text { Rp. } 1.092 / \text { lembar }
\end{aligned}
$$

Jadi dengan metode penilaian discounted free cash flow to firm diperoleh bahwa harga per lembar saham PT Ciputra Development Tbk adalah Rp. 1.092 per lembar.

\section{Metode Price Earning Ratio (PER)}

Penilaian harga saham dengan pendekatan pasar dapat dilakukan dengan perbandingan PER perusahaan sejenis. Penulis menggunakan beberapa perusahaan yang bergerak dalam bidang property yang terdaftar di Bursa Efek Indonesia untuk menentukan harga saham PT Ciputra Development Tbk (CTRA) dengan perbandingan PER.

$$
\text { PER }=\frac{\text { Market } \text { Price of share }}{\text { Earning per share }}
$$

Perusahaan - perusahaan yang dijadikan perbandingan PER adalah PT. Alam Sutra Reality Tbk (ASRI), PT. Intiland Development Tbk (DILD), dan PT. Megapolitan Development Tbk (EMDE)

Harga saham yang digunakan untuk menentukan PER masing - masing perusahaan sejenis adalah harga rata - rata penutupan per bulan dari Januari 2017 sampai Desember 2017.

Harga rata - rata penutupan per bulan APLN, ASRI dan RODA adalah sebagai berikut :

\section{Harga Rata - rata Penutupan Saham per Bulan Tahun 2017}

\begin{tabular}{|c|r|r|r|r|}
\hline Bulan & \multicolumn{1}{|c|}{ ASRI } & \multicolumn{1}{c|}{ DILD } & \multicolumn{1}{c|}{ EMDE } & \multicolumn{1}{c|}{ CTRA } \\
\hline Januari & 382 & 476 & 136 & 1.301 \\
\hline Februari & 380 & 467 & 165 & 1.375 \\
\hline Maret & 366 & 433 & 224 & 1.268 \\
\hline April & 350 & 425 & 234 & 1.224 \\
\hline Mei & 331 & 421 & 233 & 1.156 \\
\hline Juni & 323 & 423 & 225 & 1.145 \\
\hline Juli & 316 & 403 & 254 & 1.153 \\
\hline Agustus & 357 & 409 & 268 & 1.155 \\
\hline September & 369 & 418 & 300 & 1.163 \\
\hline Oktober & 389 & 416 & 299 & 1.188 \\
\hline November & 391 & 383 & 280 & 1.203 \\
\hline Desember & 354 & 368 & 246 & 1.179 \\
\hline Jumlah & $\mathbf{4 . 3 0 8}$ & $\mathbf{5 . 0 4 1}$ & $\mathbf{2 8 6 3}$ & $\mathbf{1 4 . 5 1 1}$ \\
\hline Harga Rata - rata & $\mathbf{3 5 9}$ & $\mathbf{4 2 0}$ & $\mathbf{2 3 9}$ & $\mathbf{1 . 2 0 9}$ \\
\hline
\end{tabular}

Sumber : duniainvestasi.com

Harga rata - rata penutupan saham per bulan diperoleh dengan cara menjumlahkan harga penutupan saham di perdagangan bursa pada setiap harinya selama 1 bulan kemudian dibagi dengan jumlah hari saham tersebut sehingga diperoleh harga penutupan saham bulanan.

EPS masing - masing perusahaan diambil dari laporan audit masing - masing perusahaan yang berakhir tahun 2017 . 
EPS dan PER ASRI, DILD, EMDE dan CTRA

\begin{tabular}{|l|r|r|r|r|}
\cline { 2 - 5 } \multicolumn{1}{c|}{} & \multicolumn{1}{c|}{ ASRI } & \multicolumn{1}{c|}{ DILD } & \multicolumn{1}{c|}{ EMDE } & \multicolumn{1}{c|}{ CTRA } \\
\hline EPS & 70,23 & 29 & 4,03 & 48 \\
\hline Harga Saham rata - rata & 359 & 420 & 239 & 1209 \\
\hline PER & 5,11 & 14,48 & 59,31 & 25,19 \\
\hline
\end{tabular}

Sumber : Diolah oleh Penulis

PER masing - masing saham diperoleh dari pembagian antara harga saham rata - rata selama 1 tahun yaitu tahun 2017 dengan EPS yang diambil dari laporan audit perusahaan sejenis.

Harga saham per lembar PT Ciputra Development dengan pendekatan pasar adalah Harga per lembar $=$ PER Rata-rata x EPS PT Ciputa Development Tbk 2017

Harga per lembar $=26,3 \times$ Rp. 48 / lembar

Harga per lembar = Rp. 1.262,4 / lembar

Jadi dengan pendekatan pasar PER diperoleh bahwa penilaian harga per lembar saham CTRA adalah Rp. 1.262,4 / lembar.

Hasil perhitungan diatas menunjukan bahwa harga wajar per lembar saham perusahaan PT Ciputra Development Tbk jauh lebih tinggi dari harga rata - rata saham.

\section{KESIMPULAN DAN SARAN \\ Kesimpulan}

Berdasarkan perhitungan penilaian saham PT Ciputra Development Tbk dengan menggunakan metode discounted free cash flow to firm dan price earning ratio (PER), maka dapat di simpulkan sebagai berikut :

a) Nilai wajar saham PT Ciputra Development Tbk berdasarkan metode discounted free cash flow to firm dan Price earning ratio berkisar antara Rp. 1.092 hingga $1.262,4$ per lembar.

b) Hasil pengolahan data untuk penilaian saham yang di olah oleh Penulis menunjukan bahwa harga saham PT Ciputra Development Tbk saat ini dengan menggunakan metode metode discounted free cash flow to firm adalah overvalued (harga wajar saham < harga pasar).

c) Hasil pengolahan data untuk penilaian saham yang di olah oleh Penulis menunjukan bahwa harga saham PT Ciputra Development Tbk saat ini dengan menggunakan metode metode Price earning ratio adalah undervalued (harga wajar saham > harga pasar).

\section{Saran}

Berdasarkan penilaian saham PT Ciputra Development Tbk dengan metode discounted free cash flow to firm dan price earning ratio (PER) dan kesimpulan yang telah diuraikan sebelumnya di atas, maka saran yang dapat diberikan yaitu:

- Nilai intrinsik saham yang didapat dari hasil pengolahan data dengan menggunakan metode discounted free cash flow dan price earning ratio merupakan hasil dari estimasi yang tentunya dapat menghasilkan suatu ketidakpastian, oleh karena itu sebaiknya para investor diharapkan dapat lebih berhati-hati dalam mengambil sebuah keputusan investasi. 
- Dalam menentukan keputusan investasi lebih lanjut, maka perlu dilakukan analisis yang lebih mendalam dengan mempertimbangkan kondisi internal dan eksternal dari perusahaan sehingga dapat memberikan hasil analisis yang lebih baik.

\section{DAFTAR PUSTAKA}

Copeland, Tom, T. Koller, \& J. Murrin. (2000). Valuation : Measuring and Managing the Value of Companies (Third edition ed.). New York: Jhon Wiley \& Son.

Damodara, A. (2002). Investment valuation : Tools and techniques for determining the value of any asset (2nd ed.). New York: John Wiley \& Son.

Henry Simamora. 2000. Basis Pengambilan Keputusan Bisnis. Salemba Empat. Jakarta.

Husnan, Suad. (2001). Dasar-Dasar Teori Portofolio Dan Analisis Sekuritas. AMP YPKN. Yogyakarta.

Keown, A. J., Martin, J. D., Petty, J. W., Scott Jr, \& David F. (2005). Financial Management : Principle and Applications. New Jersey: Pearson Prentice Hill.

Kismono, G. (2001). Pengantar Bisnis (Vol. Pertama). Yogyakarta: BPFE.

Noor, M. S., \& Satyawan, M. D. (2014, Juli). ANALISIS PENILAIAN HARGA WAJAR SAHAM STUDI KASUS PADA PT MULTI BINTANG INDONESIA, TBK. Jurnal Ilmu Manajemen, 2.

Parahita. 2008. Bagaimana Cara Menentukan Harga Wajar Saham. http

://parahita.wordpress.com (11 juni 2009)

Santoso, B. (2009). Property crash : kejatuhan bisnis properti dan strategi menghadapinya. Jakarta: PT. Elex Media Komputindo.

Siagian, P., \& Kasyiat. (2011, November). PENGARUH RETURN ON EQUITY, PRICE EARNING RATIO, PRICE TO BOOK VALUE DAN INFLASI TERHADAP HARGA SAHAM PT BHAKTI INVESTAMA TBK JAKARTA. Binus Business Review, 02.

Sulistyastuti, D. R. (2005). Saham dan Obligasi. Yogyakarta: Universitas Atmajaya.

Stowe, J. D., Robinson, T. R., Pinto, J. E., \& McLeavy, D. W. (2002). Analysis of Equity Investments: Valuation. Baltimore: Association for Investment Management and Research : United Book Press. 
